\title{
Chile: lejos de un milagro económico
}

\author{
Carlos García, académico FEN UAH
}

Una pregunta clave es si el magro crecimiento de la economía chilena se revertirá el 2018 o si refleja una tendencia más de largo plazo. Al respecto, como hemos explicado en números anteriores de esta misma revista, los economistas Ilaman al crecimiento del PIB de largo plazo "potencial", es decir, el crecimiento en la producción que teóricamente habría prevalecido si se utilizaran los recursos productivos con una intensidad normal y el nivel de productividad fuese el de tendencia. Este es el concepto que utiliza el Gobierno para calcular los ingresos estructurales fiscales y el Banco Central para implementar su política monetaria. También es una medida aceptada internacionalmente, que usan organismos internacionales como el FMI y la OECD.

Más especificamente, los recursos productivos son el stock de capital, el empleo ajustadas por la calidad del trabajo (educación, es decir, escolaridad promedio de la población) y la productividad total de factores o simplemente productividad. Por tanto, un análisis del crecimiento potencial pasa por determinar cuáles de estos recursos no está evolucionando a las tasas deseadas.

Según estimaciones recientes del Comité Consultivo del PIB Tendencial del Ministerio de Hacienda entre el 2017-2022, el PIB de tendencia que está en 2,6\% terminaría en 3,0\%. Porcentaje menor al 4,3\% de la década pasada y muy por debajo del 6,7\% de los años noventa. El aumento de 2,6\% a 3,0\% es dado por el mejor desempeño en la formación bruta de capital fijo, pero su menor nivel en relación con las dos décadas pasadas se explica básicamente por el estancamiento del crecimiento de la productividad.

Dado este análisis, el crecimiento de este año, en torno al 1,2\%, estaría claramente por debajo del potencial, pero el crecimiento esperado para 2018 estaría muy cerca de este valor. Por tanto, el bajo crecimiento de la economía chilena pasa ser más un tema de largo plazo que cíclico.

Con relación a este tema, la Comisión Nacional de la Productividad ha identificado áreas importantes donde la economía chilena puede mejorar en estos años. Algunas de ellas están a cargo del Gobierno, como la eficiencia regulatoria, el fomento de la competencia, y la modernización del Estado, incluyendo simplificación y digitalización de trámites. Otras, quizás las más relevantes por su magnitud corresponden a áreas del sector privado pero apoyado en parte, por el Estado, para que promuevan la inversión y están enfocadas en retomar el impulso del sector exportador de los años noventa, mejorar la calidad de la mano de obra (educación) y todo lo relacionado a emprendimiento, innovación y tecnología. Incluiría además, seguridad ciudadana e infraestructura.

Para poner los números en perspectiva, con un crecimiento de $3,0 \%$ al año, descontando el crecimiento de la población $(0,8 \%)$, tardariamos 46 años en alcanzar el PIB per cápita actual promedio de los miembros de la OECD. En cambio, con un crecimiento de casi 7,0\%, como la observada en los años noventa nos demoraríamos 17 años. Es decir, necesitariamos menos de dos décadas para generar un milagro económico.

¿Cómo generamos entonces este milagro económico de esas dimensiones? Claramente las medidas pro productividad de la Comisión Nacional de la Productividad empalidecen completamente ante las necesidades de crecer a un 7\% por dos décadas consecutivas. Se necita un cambio muy dramático para alcanzar estos niveles de crecimiento, parecido al proceso transformador que experimentó China en las últimas décadas del siglo pasado. En efecto, estamos lejos de llegar a ser un país desarrollado en el mediano plazo y bajo las actuales consecuencias, seremos eternamente un pais catalogado de "emergente".

Las alternativas para mejorar serian tomar las recomendaciones de la Comisión Nacional de Productividad y hacerlas una agenda nacional de verdad $y$, más difícil aún, radicalizarlas, es decir, imultiplicarlas por 10! Es verdad, con esta multiplicación sideral los equilibrios macroeconómicos pueden transformarse en desequilibrios agudos. Pero la alternativa es clara, una política de equilibrios nos dejará donde mismo estamos, menos pobres, limpios y ordenados. Necesitamos entonces tirar la casa por la ventana para hacer un milagro económico.

Sin duda, que resolver el tema distributivo es crítico para que el objetivo de generar un milagro económico sea un acuerdo nacional creible de largo aliento. Solo así todos remaremos en el mismo sentido, o sino el acuerdo durará tanto como los autos deportivos se demoren en llenar las calles de la Dehesa y Chicureo, simple naturaleza humana.

Finalmente, en este análisis descartamos decididamente cualquier efecto negativo de la evolución de la economía internacional. Por el contrario, el repunte del crecimiento de la economía mundial se está consolidando después de la crisis internacional de la década pasada y con ello el precio de los commodities. El pronóstico de crecimiento mundial según el FMI para 2017 y 2018 es de 3,6\% y 3,7\%, respectivamente. Básicamente, la reactivación es liderada por la inversión, el comercio internacional y la producción industrial, sumada a la mejora de la confianza de las empresas y los consumidores. Así, por ejemplo, los niveles de crecimiento registrados en el primer semestre de 2017 superaron en general las expectativas, lo cual ha llevado a revisiones al alza generalizadas en varias áreas económicas como Europa, Japón y China, socios comerciales directos de Chile.

Observatorio Económico \

Decano (I): Eduardo Abarzúa

Fono Facultad: 28897366

fen.uahurtado.cl 